\title{
Thermal studies of Martian channels and valleys using Termoskan data
}

\author{
Bruce H. Betts ${ }^{1}$ and Bruce C. Murray \\ Division of Geological and Planetary Sciences, California Institute of Technology, Pasadena
}

\begin{abstract}
The Termoskan instrument on board the Phobos '88 spacecraft acquired the highest spatial resolution thermal infrared emission data ever obtained for Mars. Included in the thermal images are $2 \mathrm{~km} /$ pixel, midday observations of several major channel and valley systems including significant portions of Shalbatana, Ravi, Al-Qahira, and Ma'adim Valles, the channel connecting Valles Marineris with Hydraotes Chaos, and channel material in Eos Chasma. Termoskan also observed small portions of the southem beginnings of Simud, Tiu, and Ares Valles and some channel material in Gangis Chasma. Simultaneous broadband visible reflectance data were obtained for all but Ma'adim Vallis. We find that most of the channels and valleys have higher thermal inertias than their surroundings, consistent with previous thermal studies. We show for the first time that the thermal inertia boundaries closely match flat channel floor boundaries. Also, buttes within channels have inertias similar to the plains surrounding the channels, suggesting the buttes are remnants of a contiguous plains surface. Lower bounds on typical channel thermal inertias range from 8.4 to $12.5\left(10^{-3} \mathrm{cal} \mathrm{cm}^{-2} \mathrm{~s}^{-1 / 2} \mathrm{~K}^{-1}\right)$ (352 to 523 in SI units of J m-2 $\mathrm{s}^{-1 / 2} \mathrm{~K}^{-1}$ ). Lower bounds on inertia differences with the surrounding heavily cratered plains range from 1.1 to 3.5 (46 to 147 SI). Atmospheric and geometric effects are not sufficient to cause the observed channel inertia enhancements. We favor nonaeolian explanations of the overall channel inertia enhancements based primarily upon the channel floors' thermal homogeneity and the strong correlation of thermal boundaries with floor boundaries. However, localized, dark regions within some channels are likely aeolian in nature as reported previously. Most channels with increased inertias have fretted morphologies such as flat floors with steep walls. Eastem Ravi and southem Ares Valles, the only major channel sections observed that have obvious catastrophic flood bedforms, do not have enhanced inertias. Therefore, we favor fretting processes over catastrophic flooding for explaining the inertia enhancements. We postulate that the inertia enhancements were caused either by the original fretting process or by a process involving the bonding of fines due to an increased availability of water, either initially or secondarily.
\end{abstract}

\section{INTRODUCTION}

Enormous channels and valleys are some of Mars' most intriguing features. Most, including those studied here, are now generally accepted to have been cut by water or ice related processes [Carr, 1981; Baker, 1982; Baker et al., 1992]. These processes probably included catastrophic flooding and sapping processes. Studies of Martian channel surface properties and morphologies yield important implications for Mars' geologic, hydrologic, and climatic history.

The Soviet Phobos '88 Termoskan instrument provided the highest spatial resolution thermal data obtained so far for Mars [Selivanov et al., 1989; Murray et al., 1991; Betts, 1993], including observations of several large equatorial channels and valleys. Here we present the results of the first detailed study of channels using the Termoskan data. We include a description of the instrument and the observations, a description of the channels observed, a review of geologic classifications and previous thermal studies, qualitative results and implications, quantitative thermal inertia determinations and implications, critiques of possible hypotheses, and proposed tests using future Mars

\footnotetext{
1Now at the San Juan Capistrano Research Institute, San Juan Capistrano, Califomia.

Copyright 1994 by the American Geophysical Union.
}

Paper number 93JE03173.

0148-0227/94/93JE03173\$05.00 missions. The term channel has been widely used for Mars, although it is somewhat erroneous in its usage [Sharp and Malin, 1975; Carr, 1981]. For simplicity, we use the term channel to refer collectively to features previously classed as channels or valleys.

\section{BACKGROUND}

\section{The Termoskan Instrument and Data}

In February and March 1989 the Termoskan instrument on board the Phobos ' 88 spacecraft of the USSR acquired a limited set of very high spatial resolution simultaneous observations of reflected solar flux and emitted thermal flux from Mars' equatorial region. These image panoramas cover a large portion of the equatorial region from $30^{\circ} \mathrm{S}$ to $6^{\circ} \mathrm{N}$ latitude. Termoskan was an optical-mechanical scanning radiometer with one visible channel (0.5-1.0 $\mu \mathrm{m})$ and one thermal infrared channel (8.5-12.0 $\mu \mathrm{m})$. The instrument was fixed to the spacecraft, pointing in the antisolar direction. Thus, all observations are at $0^{\circ}$ phase angle and only daytime observations were acquired. More complete descriptions of the Termoskan instrument and data appear in Murray et al. [1991] and Betts [1993].

Termoskan's best resolution per pixel was $1.8 \mathrm{~km}$ for three of the panoramas acquired and $300 \mathrm{~m}$ for the remaining panorama [Selivanov et al., 1989; Murray et al., 1991]. These resolutions are much better than those obtained by the Viking infrared thermal mapper (IRTM) (approximately 5 to $170 \mathrm{~km} /$ pixel, with only a small fraction of the data near $5 \mathrm{~km} / \mathrm{pixel}$, and a typical 
value of 30 [Christensen, 1986]). Termoskan's spatial resolution is also better than the $3 \mathrm{~km} /$ pixel that was expected for Mars Observer's thermal emission spectrometer (TES), although TES observations would have provided global 1400 and 0200 local time (LT) spectral coverage.

Thermal inertia, a bulk measure of the resistance of a unit surface area to changes in temperature, is commonly used to characterize the insulating properties of planetary surfaces. It is defined as $I=\left(k p c_{p}\right)^{1 / 2}$, where $k$ is the thermal conductivity, $p$ is the density, and $c_{p}$ is the specific heat. Low-inertia materials exhibit the largest day-to-night temperature variation and the smallest thermal skin depths. We use the units for thermal inertia often used for the Martian surface [e.g., Kieffer et al., 1977]: $10^{-3} \mathrm{cal} \mathrm{cm}^{-2} \mathrm{~K}^{-1} \mathrm{~s}^{-1 / 2}$. Thermal inertias in SI units $\left(\mathrm{J} \mathrm{m}^{-2}\right.$ $\mathrm{K}^{-1} \mathrm{~s}^{-1 / 2}$ ) can be obtained by multiplying by 41.86 .

\section{Channel Descriptions and Geographic and Geologic Settings}

Termoskan observed several large channels near the eastern end of Valles Marineris including significant portions of Shalbatana Vallis, Ravi Vallis, the channel connecting Valles Marineris with Hydraotes Chaos, and channel material in Eos Chasma. In the same region, Termoskan also observed small portions of the southern beginnings of Simud, Tiu, and Ares Valles as well as channel material in the northern portions of Gangis Chasma. On the other side of the planet, Termoskan observed two major valleys in the Aeolis Quadrangle: Al-Qahira Vallis and Ma'adim Vallis (see Table 1). All the channel sections observed by Termoskan cut through ancient cratered terrain of Noachian age [Scott and Tanaka, 1986; Greeley and Guest, 1987].

Shalbatana Vallis (see Figure 1) appears to emanate from a zone of chaotic terrain at $0^{\circ} \mathrm{N}, 46^{\circ} \mathrm{W}$ and heads northward. It narrows to a low-sinuosity channel with a reasonably uniform width of approximately $10 \mathrm{~km}$. It eventually splits into two distributaries. In all, it extends over $1000 \mathrm{~km}$. Termoskan observed approximately the southern $400 \mathrm{~km}$ of the channel. Just to the east of Shalbatana is the $300-\mathrm{km}$-long Ravi Vallis, which also emanates from a region of chaotic terrain (Aromatum Chaos). The channel thins and proceeds east, eventually ending in the western portion of Hydraotes Chaos. In contrast with most of the channels discussed here, eastern Ravi has grooved terrain on its floor. In addition, its walls are not as high or as steep as those of the other observed channels.
In addition to Ravi Vallis, several other channels lead either into or out of Hydraotes Chaos (see Figure 1). A large, flat channel enters Hydraotes Chaos from Valles Marineris to the south. We will refer to this channel by the unofficial name, Hydraotes Channel. Regions of chaotic terrain occur both to the south and to the north of this channel. Another flat, steep walled channel at the northwest corner of Hydraotes Chaos begins Simud Vallis. Only approximately $75 \mathrm{~km}$ of this channel were observed north of the chaos. At the northeast corner of Hydraotes Chaos, Termoskan observed about $150 \mathrm{~km}$ of a channel (here called Tiu West) that splits around a large butte. This channel then meets another observed channel (here called Tiu East) coming from Hydaspis Chaos to the east. When these sets of channels meet north of the Termoskan coverage area, they form Tiu Vallis proper. Small portions of the headward reaches of Ares Vallis were also observed. Most of this part of Ares does not show flat floors, but rather appears scoured and is locally anastomotic [Sharp and Malin, 1975]. Simud, Tiu, and Ares, like Shalbatana Vallis, all debouch into Chryse Planitia several hundred kilometers downstream.

Channel materials were also observed in two of the eastern Valles Marineris Chasma: Eos and Gangis (see Figure 1). Flow from these regions presumably headed to the east and eventually northeast in the direction of Hydraotes Channel and Chaos. Only the northernmost part of Gangis was observed. A separate Termoskan panorama shows most of Eos Chasma. Both chasma contain flat, smooth appearing areas classified by Scott and Tanaka [1986] as Hesperian channel materials. The channel materials are situated next to steep walls, buttes, and at least in Eos Chasma, between regions of chaotic terrain.

Termoskan also observed Ma'adim Vallis and A1-Qahira Vallis, two isolated channels in the Aeolis quadrangle. Termoskan observed the northernmost (distal) $350 \mathrm{~km}$ of the 700 $\mathrm{km}$ long, gently winding, $15-$ to $25-\mathrm{km}$-wide Ma'adim Vallis. It heads northward until hooking northwest after breaching a $30-\mathrm{km}$ crater. It debouches into another $30-\mathrm{km}$ crater. Ma'adim is unusually old for a large channel [Baker, 1982; Masursky et al., 1980]. Ma'adim has steep walls and smooth floors except where benches exist.

Al-Qahira Vallis is located approximately $800 \mathrm{~km}$ to the west of Ma'adim. Termoskan observed all $300 \mathrm{~km}$ of this channel. It originates from short tributaries, runs mainly east, then turns north and widens as it takes a very straight course. It also has a

TABLE 1. Channel Locations, Seasons Observed, and Types

\begin{tabular}{|c|c|c|c|}
\hline Channel & Channel section observed & $L_{8}$ & Type \\
\hline Al-Qahira & $20^{\circ} \mathrm{S}, 199^{\circ} \mathrm{W}$ to $14^{\circ} \mathrm{S}, 195^{\circ} \mathrm{W}$ & $18^{\circ}$ & Runoff channel [M76]; longitudinal valley [B92]; fretted channel [C81] \\
\hline Ma'adim & $20^{\circ} \mathrm{S}, 183^{\circ} \mathrm{W}$ to $16^{\circ} \mathrm{S}, 184^{\circ} \mathrm{W}$ & $18^{\circ}$ & Runoff channel [SM75]; longitudinal valley [B92]; fretted channel [C81] \\
\hline Shalbatana & $2^{\circ} \mathrm{S}, 46^{\circ} \mathrm{W}$ to $5^{\circ} \mathrm{N}, 44^{\circ} \mathrm{W}$ & $6^{\circ}$ & Outflow channel [SM75] \\
\hline $\begin{array}{l}\text { Hydraotes Channel, } \\
\text { Simud, and Tiu Valles }\end{array}$ & $7^{\circ} \mathrm{S}, 36^{\circ} \mathrm{W}$ to $5^{\circ} \mathrm{N}, 37^{\circ} \mathrm{W}$ & $6^{\circ}$ & $\begin{array}{l}\text { Simud and Tiu: outflow channels [SM75]; the observed portion of Simud: } \\
\text { fretted [S73] }\end{array}$ \\
\hline Ravi Vallis & $2^{\circ} \mathrm{S}, 44^{\circ} \mathrm{W}$ to $0^{\circ} \mathrm{N}, 39^{\circ} \mathrm{W}$ & $6^{\circ}$ & Outflow channel [B82] \\
\hline Ares Vallis & $1^{\circ} \mathrm{S}, 16^{\circ} \mathrm{W}$ to $5^{\circ} \mathrm{N}, 19^{\circ} \mathrm{W}$ & $6^{\circ}$ & Outflow channel [SM75] \\
\hline Eos Chasma & $15^{\circ} \mathrm{S}, 44^{\circ} \mathrm{W}$ to $10^{\circ} \mathrm{S}, 37^{\circ} \mathrm{W}$ & $18^{\circ}$ & \\
\hline Gangis Chasma & $8^{\circ} \mathrm{S}, 49^{\circ} \mathrm{W}$ to $7^{\circ} \mathrm{S}, 44^{\circ} \mathrm{W}$ & $6^{\circ}$ & \\
\hline
\end{tabular}




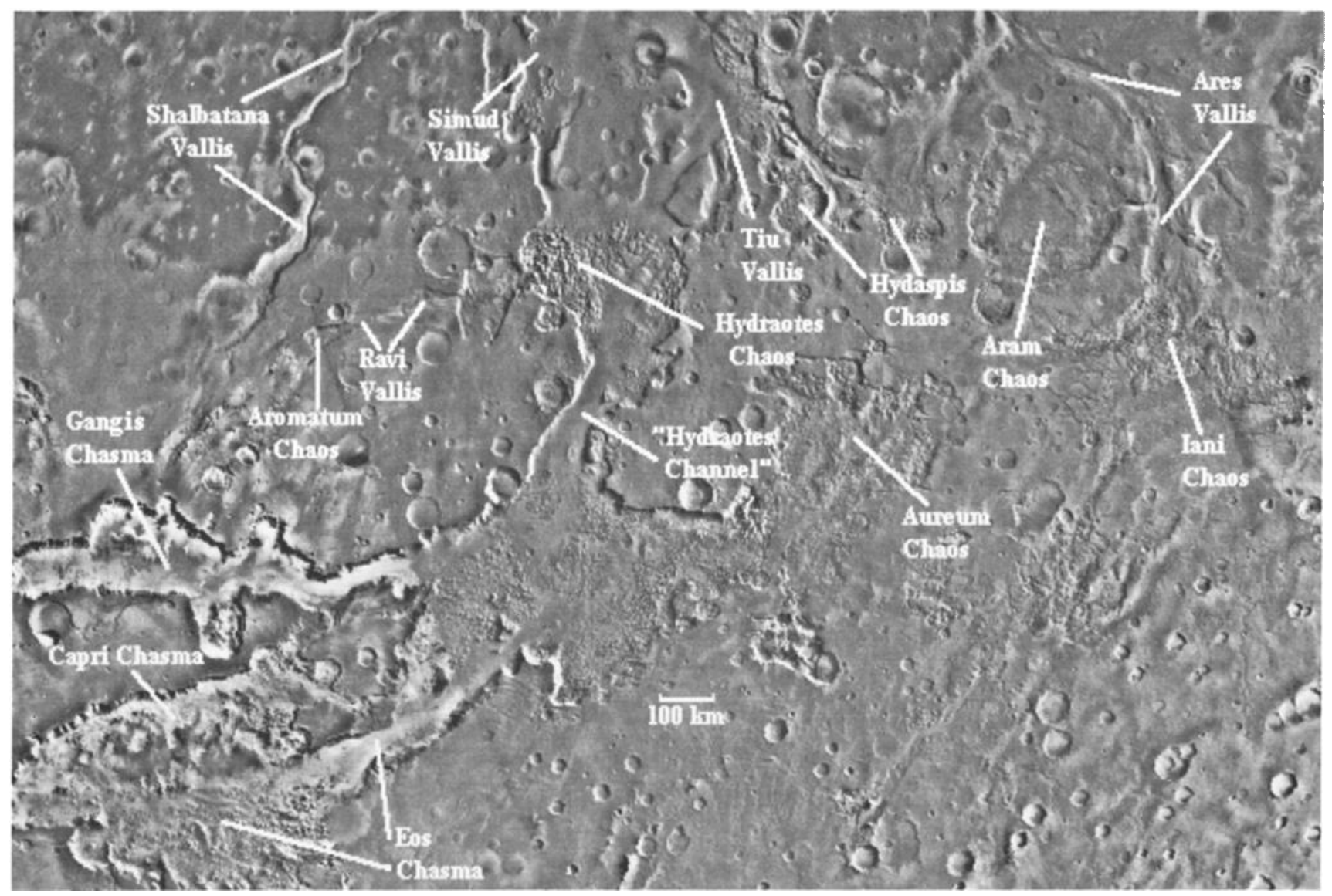

Fig. 1. Viking photomosaic (a portion of file MEO0N045 from U.S. Geological Survey [1991a]) of the channels studied in the eastern Vallis Marineris region centered approximately upon $4^{\circ} \mathrm{S}, 33^{\circ} \mathrm{W}$. North is at top in all image figures. Note that virtmally all the channels have smooth flat floors and steep, scalloped walls, suggestive of fretting.

broad, flat floored main channel and heavy cratering [Baker, 1982]. Like Ma'adim, its termination is rather indistinct and shows a marked lack of large scale deposits.

\section{Channel Classifications}

Martian channels have been classified by several authors. Table 1 summarizes previous geologic classifications for the observed channels. All of the named channels in the eastern Valles Marineris region are classified at least in part as outflow channels [e.g., Sharp and Malin, 1975; Carr, 1981; Baker, 1982; Baker et al., 1992]. These include Shalbatana, Ravi, Tiu, Simud, and Ares. Sharp and Malin [1975] define outflow channels as mostly large features that start full-born from localized sources. They are broadest and deepest at their head. Some are scoured and display features characteristic of catastrophic flooding. Many originate from chaotic terrain. Outflow channels are generally accepted to have originally formed by catastrophic flooding, in some cases from release of water from chaotic terrain [Baker et al., 1992; Carr, 1986].

Sharp and Malin [1975] classed Ma'adim Vallis as a runoff channel, and Mutch et al. [1976] classed Al-Qahira Vallis (which was not discussed by Sharp and Malin) as a runoff channel. Sharp and Malin [1975] define runoff channels as starting small, increasing in size and depth distally and having tributary branches, and crustal control may be strong. Baker et al. [1992] class Ma'adim and Al-Qahira Vallis as longitudinal valleys. Mars Channel Working Group [1983] distinguished Martian valleys from channels by the absence of bedforms indicative of fluvial flow. Longitudinal valleys may have begun as small valleys, then become enlarged by wall retreat as lower courses became deeply incised [Baker et al., 1992].

Carr [1981] classes Al-Qahira and Ma'adim as fretted channels. Indeed, whatever caused the original valleys, the wide, flat floors and steep walls with scalloped appearances indicate that a fretting process [Sharp, 1973] has been active for Ma'adim and Al-Qahira. Fretting presumably involved sapping of groundwater or ice, causing undercutting of the walls. Debris flows, possibly facilitated by ice (as suggested for fretted terrain by Squyres [1978]), may have then moved material away from the walls, allowing more undercutting erosion to occur. We emphasize, however, that fretting is not a well-understood process, but it is morphologically well defined for Mars.

Fretting also appears to have occurred in the portions of channels observed by Termoskan near eastern Valles Marineris. Again this is based upon the steep walls and flat, smooth floors. In fact, the channel at the northwest of Hydraotes Chaos (leading to Simud) is specifically shown by Sharp [1973] as an example of fretted channels next to chaotic terrains. Thus, many of the channels observed show evidence of fretted morphologies, indicating that fretting was at the very least the last major process to influence their large scale morphology. Notable exceptions are eastern Ravi Vallis and southern Ares Vallis, which do not have walls that are as steep and which have rough floor features, including features such as grooves that are indicative of catastrophic flooding. Termoskan observed few classic outflow channel morphologies, although it narrowly 
missed several north of the area at the eastern end of Valles Marineris. Extension of this analysis to more classic outflow channels using future mission data will be very interesting.

\section{Previous Thermal Studies}

Several researchers have undertaken thermal studies of Martian channels and valleys using Viking IRTM data. These analyses and the channels studied include Christensen and Kieffer [1979], Kasei, Ares, Shalbatana, Simud, and Tiu Valles; Zimbelman [1986] and Zimbelman and Leshin [1987] Al-Qahira and Ma'adim Valles; and Craddock et al. [1988] and Craddock [1987], Dao, Hormakis, Ma'adim, Mangala, and Shalbatana Valles. These studies concluded that many channels and valleys have higher thermal inertia than their surroundings. In explaining the cause of the inertia enhancements, these studies emphasized the presence of dark, high-inertia, presumably aeolian saltation deposits within the channels.

Zimbelman [1986] and Craddock et al. [1988] concluded that several centimeter thick aeolian deposits dominate the inertia of the channel floors. At least for the channels they studied, they concluded that thermal observations may not be related to the processes that produced the channels. In contrast, we conclude that thermal observations of much of the channel floors may be sampling some material and textures from channel floor formation. IRTM studies of channels were limited either by insufficient spatial resolution to resolve the channels or by limited areal coverage of the highest-resolution data. In contrast, Termoskan data provide high-resolution images with nearly complete spatial coverage (i.e., no gaps or gores).

\section{QUALTTATIVE ANALYSES}

\section{Observations}

Termoskan obtained thermal images of several channels in the eastern Valles Marineris region (see Figures 2, 3, and 4) and of Al-Qahira Vallis (Figure 5) and Ma'adim Vallis (Figure 6). Simultaneous broadband visible channel data were obtained for all but Ma'adim Vallis. All of the channel systems were observed near midday, between $9.87 \mathrm{H}$ and $13.00 \mathrm{H}$, except Eos Chasma at $15.15 \mathrm{H}$ (where $24 \mathrm{H}=1 \mathrm{Martian}$ day). All were observed with an approximate resolution of $1.8 \mathrm{~km} / \mathrm{pixel}$ and at nearly $0^{\circ}$ phase angle. Mangala Vallis was also observed, but we do not discuss it in detail. The Mangala data are badly foreshortened and interpretation is further complicated by the early morning (postdawn) and late afternoon (presunset) local times of the observations.

The general characteristics of all the channel observations are summarized in Table 2. Termoskan's high-resolution images show for the first time that thermal boundaries very closely match channel floor boundaries, usually to within the resolution of the instrument. For these midday observations, the cooler and darker (or similar albedo) channels must have higher thermal inertia than their surroundings. The eastern end of Ravi Vallis and southern Ares Vallis appear different from most of the other channel observations. They do not have flat floors or steep walls, and they appear thermally similar to their surroundings. Thermal distinctiveness within channels is strongly correlated with regions that have morphologies indicative of fretting: flat wide floors and steep, scalloped walls. Comparisons are limited, however, because few other channel types were observed by Termoskan except Ravi and Ares, although many occur elsewhere on the planet.

\section{Implications}

We can draw the following conclusions from the qualitative observations listed in Table 2 :

1. The floors of virtually all the channels observed consistently have higher inertia (implying coarser material, more bonded material, or more rocks) than their surroundings, consistent with previous studies.

2. Boundaries of thermal inertia (which represents the upper few centimeters of the surface) closely match channel floor boundaries, particularly for wide, flat floors.

3. Dark, presumably acolian deposits, do not dominate the inertia of the channels as a whole. This contrasts with conclusions drawn by some previous researchers [Zimbelman, 1986; Craddock et al., 1988], whose results were based upon lower-resolution, nonimaging IRTM data. In Termoskan observations, channel inertias are still higher than those of the surroundings even outside the localized, dark deposits. The dark deposits are very likely saltation traps for dark sand, similar to the localized intracrater deposits seen near some channels and investigated planet-wide by Christensen [1983]. We discuss this more fully in the aeolian explanations section.

4. Channels are examples of features whose inertia correlates well with morphology, which is rare on Mars [Christensen and Moore, 1992].

\section{QUANTITATIVE THERMAL INERTIA DETERMINATION}

\section{Method}

We have used the Termoskan data in combination with thermal modeling and albedo information from Viking to derive thermal inertias for points within channels and for points on the surrounding plains. For Al-Qahira and Ma'adim Valles, we chose approximately 10 locations inside and 10 outside each channel. For the other, shorter, channel segments, one representative channel point and one representative surrounding point were chosen. Points inside each channel were selected to represent the channel, to avoid large slopes that would significantly alter inertia determinations, and for Al-Qahira and Ma'adim, to give good coverage over the length of the channel. For each location inside, a paired point devoid of extreme slopes was chosen nearby on the surrounding plains. Areas were determined to be devoid of extreme slopes based upon a lack of apparent sun-facing (bright and warm) or anti-sun-facing (dark and cool) slopes based upon both Termoskan data and Viking Orbiter camera images. For each location, we noted the temperature and visible signal from single Termoskan pixels. These single-pixel values generally matched to within $1 \mathrm{~K}$ and often to within $0.5 \mathrm{~K}$ of the average of a $3 \times 3$ pixel box (if the box was entirely within the channel). Latitude and longitude were determined from USGS photomosaics. Local time of day was calculated for each point based upon its longitude and the absolute time of the observation.

To derive thermal inertias, we used an adaptation of the Clifford et al. [1987] finite difference, homogeneous thermal model of the Mars surface. This model numerically solves the heat diffusion equation using the boundary conditions of thermal equilibrium at the surface and no heat flow across the lower boundary. Physically, this model is identical to the Viking thermal model described by Kieffer et al. [1977, Appendix 1], although computationally it differs slightly.

Ideally, thermal inertia is determined from diurnal observations using temperature alone, as was done for example 

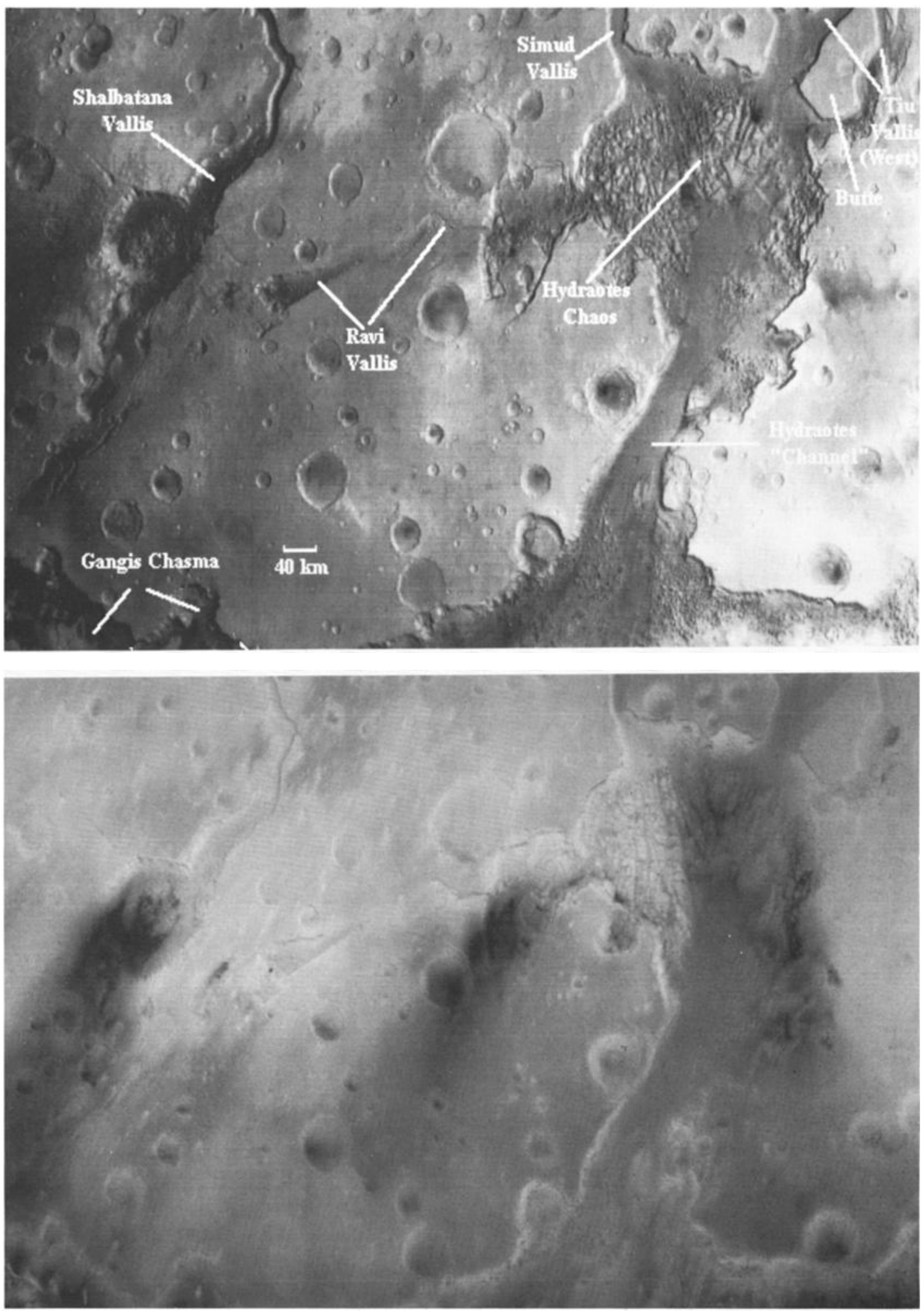

Fig. 2. (Top) Termoskan thermal and (bottom) visible images centered approximately upon $1^{\circ} \mathrm{S}, 39^{\circ} \mathrm{W}$. North is top. In all thermal images shown here, darker is cooler. Shalbatana, Simud, and Tiu Valles all continue for several hundred kilometers north of this image. Note the cool and generally uniform floors of all channels except the eastem (and rough floored) end of Ravi Vallis. Note also that the thermal boundaries closely match the boundaries of the channel floors and depart significantly from albedo boundaries seen in the visible image. Note also the dark, presumably aeolian deposits localized within the southem portions of Shalbatana Vallis and the southwestem portion of Hydraotes Chaos and spreading onto the surrounding plains in both cases. Buttes, including the large labeled one in the northeast of the image, within the channels appear similar in temperature and appearance to the surrounding plains, not the channels. 

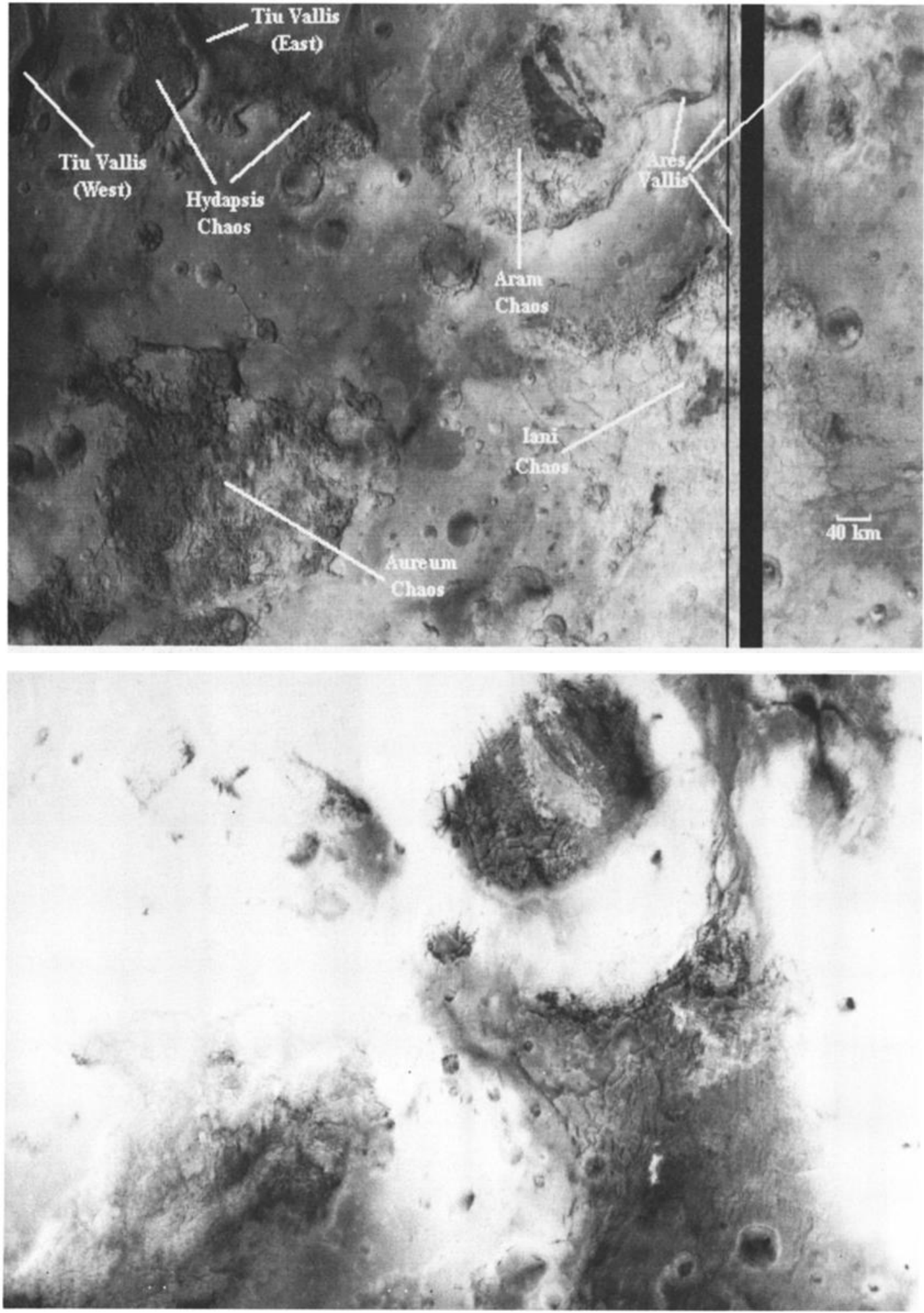

Fig. 3. (Top) Termoskan thermal and (bottom) visible images centered approximately upon $1^{\circ} \mathrm{S}, 23^{\circ} \mathrm{W}$. North is top. Westem portion overlaps slightly with Figure 2 . Vertical black lines have been added where lines were missing in the original data. Note that the central part of Ares Vallis that runs north from Iani Chaos is not thermally distinct from its surroundings. This region shows significant catastrophic flooding bedforms and lacks fretting morphologies. The smaller channels that join the central Ares channel from the west and from the east are in some areas cooler. However, as opposed to most other channels, the cooler areas occur in patches, possibly indicative of aeolian processes.

by Palluconi and Kieffer [1981] and Kieffer et al. [1977]. However, Termoskan acquired only one observation of each of the channels studied. Thus, we use an alternate method that uses a single temperature observation combined with bolometric albedo (similar to what was described by Kieffer et al. [1977] and used by Christensen [1983] and others). We solve for the inertia, $I$, in the expression

$$
T_{\mathrm{obs}}=T_{m}+\frac{\partial T_{m}}{\partial I\left(I-I_{m}\right)}
$$



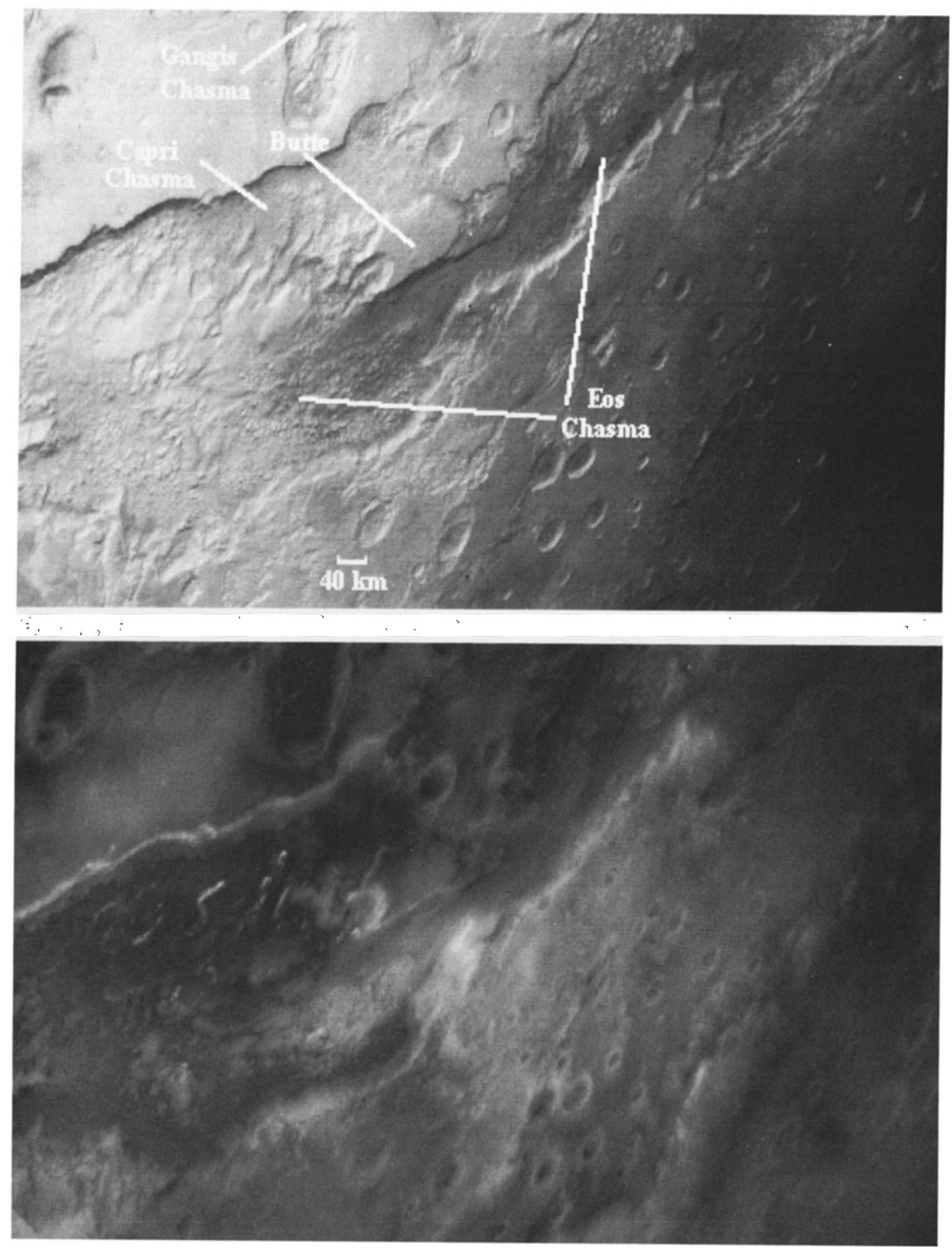

Fig. 4. (Top) Termoskan thermal and (bottom) visible images showing Eos Chasma and centered approximately upon $14^{\circ} \mathrm{S}$, $41^{\circ}$ W. Within Eos Chasma, flat floored channel floor materials [Scott and Tanaka, 1986], for example south of the labeled butte, are cool relative to surroundings.

where $T_{\mathrm{obs}}$ is the observed Termoskan brightness temperature. $I_{m}$ is the standard model inertia of 8.0 , which was chosen as a representative midpoint inertia for the channels studied. $T_{m}$ is a standard model temperature. $T_{m}$ was determined by first modeling the surface using an inertia of $I_{m}$, an albedo of $A_{m}$ (discussed below), and the correct Martian season $\left(L_{s}=6^{\circ}\right.$ or $L_{s}=18^{\circ}$, where $L_{s}$ is the areocentric solar longitude). The model produced temperature outputs for every $0.25 \mathrm{H}$ and for every $2^{\circ}$ latitude. The temperature outputs were then interpolated for each locations' latitude and time of day to give $T_{m}$. To derive $\partial T_{m} \partial I$, we used an identical process to derive model temperatures for other values of inertia. We used inertias near $I_{m}$ (within 1.5 units) to minimize errors in $\partial T_{m} / \partial I$ caused by the nonlinearity of temperature with inertia. 

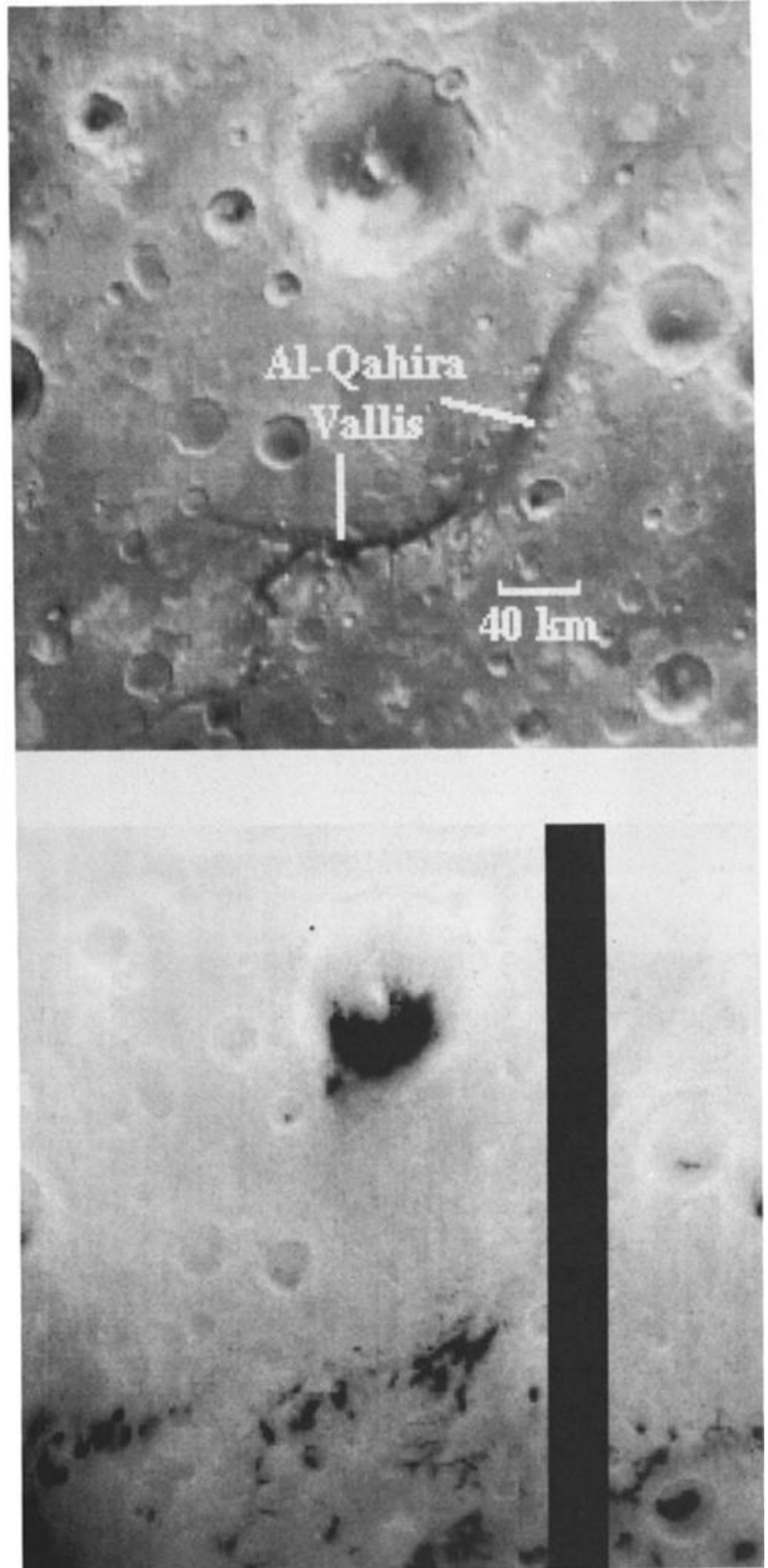

Fig. 5. (Top) Termoskan thermal and (bottom) visible images showing Al-Qahira Vallis and centered approximately upon $17^{\circ} \mathrm{S}, 197^{\circ} \mathrm{W}$. Vertical black lines have been added where lines were missing in the original data. Al-Qahira Vallis shows smooth broad floors, a tributary pattern, and a straight, possibly structurally controlled, northem section. Note dark, presumably aeolian, material localized in the southern portions of the valley and on the surrounding plains, and in the large crater to the northwest of the valley. The channel floors appear cooler than the surroundings both where the dark deposits are and where they are not.

Bolometric albedo $\left(A_{m}\right)$ is required when deriving inertias using single observations. Due to instrument limitations, atmospheric variations, and very limited phase angle viewing geometry, even approximate estimates of bolometric albedo from the Termoskan data have thus far not yielded high confidence results [Murray et al., 1991; Betts, 1993]. Thus, we use bolometric albedos from the $1^{\circ} \times 1^{\circ}$ binned albedos of Pleskor and Miner [1981]. We averaged adjacent bins along the course of the channels. Generally, the albedos varied by less than 0.01 for all bins surrounding and including the channels. The albedo values we used in our model for each channel are shown in Table 3. Due to its large width, Hydraotes channel is the only channel for which we could estimate an albedo separate from the surroundings.

Most of the channels are significantly narrower than the $1^{\circ} \mathrm{x}$ $1^{\circ}$ bin size of Pleskot and Miner [1981]. Thus, the Pleskot and Miner albedos are likely good estimates for the surroundings, but not necessarily for the channels. The Termoskan data show that
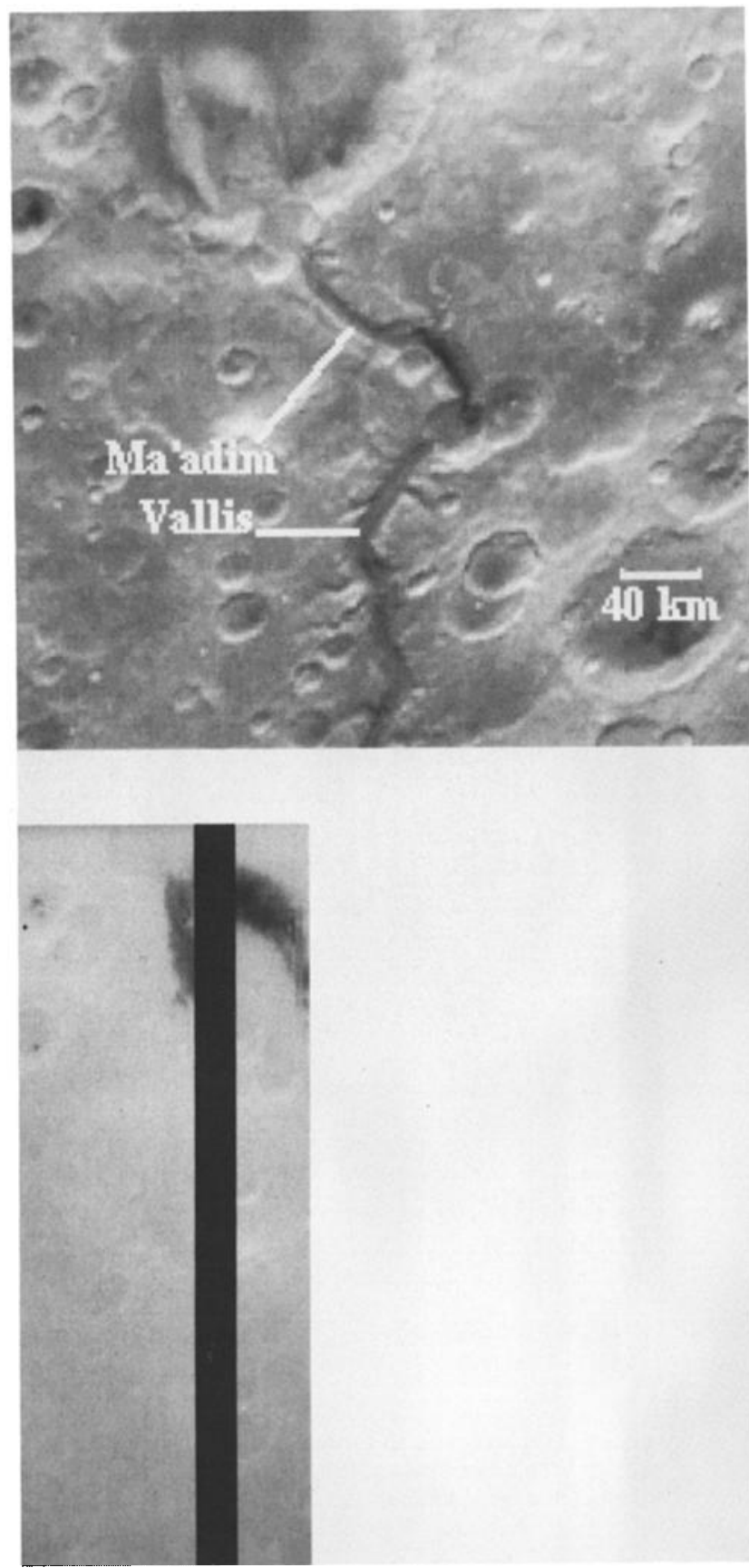

Fig. 6. (Top) Temoskan thermal and (bottom) visible images showing Ma'adim Vallis and centered approximately upon $17^{\circ} \mathrm{S}, 183^{\circ} \mathrm{W}$. Visible data were only obtained in the westem portion of this region. Once again, note how cool ternperatures follow channel floor. Localized cooler spots may have aoolian causes, but overall cooler channel temperatures probably do not. 


Thermal
- Channel floors consistently cooler than surroundings by $3 \mathrm{~K}$ to
$10 \mathrm{~K}$
- Thermal boundaries closely follow channel floor boundaries
- Relatively uniform on floors of channels
- Homogeneous floors even in serpentine regions around buttes
- Visible boundaries do not closely match thermal boundaries
- Channel floors cooler than surroundings even outside dark,
localized aeolian deposits. Temperature corresponds better to
floor boundaries than to dark deposits' boundaries
- Where benches along walls exist, their temperatures are
between those of the flat channel floors and those of the
surroundings
- Tributaries generally appear thermally distinct from their
surroundings
- Landslides and ejecta blankets appear thermally similar to
surrounding channel floors, although they are just at the limit
of resolution of the Termoskan data, so this observation is
guarded

the channel floors are actually all darker or similar in albedo to their surroundings. Therefore, considering the midday local times of the observations, our model results represent lower bounds for the channel inertias. Similarly, we determine lower bounds for the inertia differences between channels and surroundings. For the albedos, inertias, and times of day involved, we found that a decrease in model albedo of 0.01 would cause a derived inertia increase of approximately 0.4 . Due to its large width, we were able to estimate an albedo from Pleskot and Miner [1981] for Hydraotes Channel of approximately 0.17 versus surrounding albedos of approximately 0.20 to 0.21 . Hydraotes Channel also showed the largest difference in visible signal (DN) between channel and surroundings of any of the channels except within dark, localized aeolian splotches. Thus, an 0.04 decrease from the albedos used represents an approximate lower bound on channel albedos. This corresponds to an approximate upper bound on possible channel inertia increases relative to derived inertias of 1.6 due to albedo uncertainties.

\section{Results}

Our quantitative results back up the qualitative conclusion that all locations on the channel floors have higher inertias than the surroundings. Figure 7 and Table 3 show our derived average inertias and results from previous IRTM studies. Lower bounds on typical channel thermal inertias range from 8.4 to 12.5 (352 to 523 in SI units). The lower bounds on the average inertia difference between the channel floors and the surroundings varied from 1.1 (46 SI) for Simud Vallis to 3.5 (147 SI) for Hydraotes Channel. Our derived inertias for the surroundings are in good agreement with the corresponding $2^{\circ} \times 2^{\circ}$ binned inertias of Palluconi and Kieffer [1981], with the average inertia difference (Termoskan derived inertia minus Palluconi and Kieffer inertia) between paired points being +0.3 with a standard deviation of 0.8 .
For A1-Qahira and Ma'adim Vallis, where Termoskan obtained significant length coverage, there are no systematic differences in inertia with distance along the lengths of each channel. Also, there is no correlation between channel widths and inertia, as reported for some other channels [Craddock et al., 1988; Christensen and Kieffer, 1979].

Also of interest are buttes ("islands") seen prominently in Hydraotes Channel and in Eos Chasma. These include the $70 \mathrm{~km}$ $x 140 \mathrm{~km}$ butte at $3^{\circ} \mathrm{N}, 32^{\circ} \mathrm{W}$ between Hydraotes Chaos and Tiu Vallis (Figure 2). Although surrounded by channels, the buttes have inertias similar to the plains surrounding the channels. This is consistent with the results found by Christensen and Kieffer [1979] for a $20 \times 90 \mathrm{~km}$ butte within Kasei Vallis. Thus, as they concluded for the Kasei Vallis region, our results imply that the buttes were part of a contiguous surface prior to channel formation. The processes that led to the development of the butte and plateau surfaces probably acted prior to channel formation. Less likely, the buttes and plateaus may be currently modified by a similar process. However, this process would have to have affected them despite the presence of the channels and without affecting the surface properties of the channels.

\section{WhY Do CHANNELS AND VALLEYS HAVE HIGHER INERTIA?}

\section{In General}

The Termoskan data are consistent with the idea developed for Kasei Vallis by Christensen and Kieffer [1979] that one process, possibly associated with channel formation, increased the inertia throughout the channels. A second, probably aeolian, process concentrated a coarse, low-albedo component in certain areas. Here we assume that the low-albedo localized areas are indeed aeolian in nature. We find the more general inertia enhancements to be strongly associated with fretting. We postulate that the inertia enhancements were caused either by the original fretting process or by a process involving the bonding of 


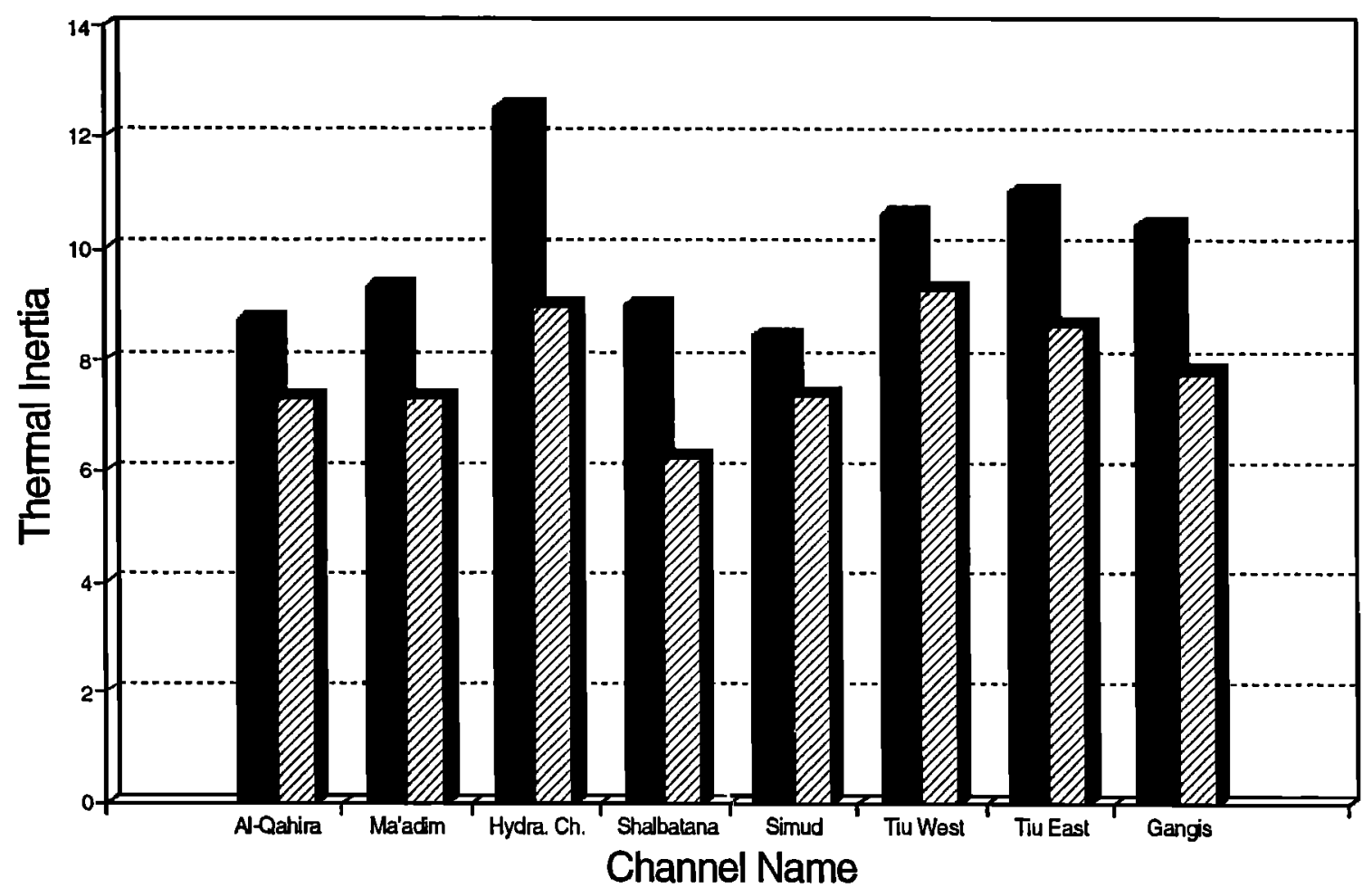

Avg. Channel Iner. $\mathbb{Z} \mathbb{A}$ Avg. Surround. Iner

Fig. 7. Inertias derived from Termoskan data for thermally distinct channels and the associated surrounding plains. Derived inertias for Eos Chasma and surroundings are not shown because they are unreasonably high due to the aftemoon cooling effect (see Table 3 for further explanation). Also not shown are Ares and Ravi Valles, which are mostly similar in inertia to their surroundings.

fines due to an increased availability of water. Before discussing fretting in more detail, we first consider alternate origins of the apparent overall inertia enhancement: atmospheric or geometric effects, aeolian causes, or catastrophic flooding causes.

\section{Atmospheric and Geometric Effects}

Two atmospheric effects will increase the apparent inertia of a surface with decreasing elevation [Christensen and Kieffer, 1979]: an increase in surface conductivity with increasing pressure and an increase in apparent inertia with increasing thermal opacity due to atmospheric dust. Over a range of elevations representative of one of the most extreme channelsurroundings elevation differences $(-2 \mathrm{~km}$ to $1 \mathrm{~km}$ in Hydraotes Channel [U. S. Geological Survey, 1991b]), the apparent thermal inertia will change due to pressure variation from 6.3 to 6.8 for a surface whose actual inertia is 6.5 at $0 \mathrm{~km}$ [Kieffer et al., 1973]. With a visible opacity of 0.3 at $-2 \mathrm{~km}$ and a scale height of 10 $\mathrm{km}$, the apparent inertia could increase from 6.5 at $1 \mathrm{~km}$ to 6.8 at $-2 \mathrm{~km}$ [Haberle and Jakosky, 1991]. Thus, although these effects may accentuate temperature differences, they are too small to explain solely the observed inertia differences.

Increased morning and late afternoon cooling in the channels due to shadowing also is not a major effect. Because of the shadowing effects of the walls, sunrise will occur later and sunset earlier in channels than on the surrounding plains. This will cool the channel floors. However, observationally, we infer this is probably not significant for the channels studied because the channel floors are cooler than the surroundings no matter what their orientation, east-west or north-south. Theoretical modelling shows that for the widths (tens of kilometers) and depths (few hundred meters and in rare cases up to $3 \mathrm{~km}$ ) of the channels studied, the decrease in overall flux due to this effect is very small because of the low sun angles and small amounts of time involved. Specifically, we calculated the decrease in energy received at the surface to be less than $0.1 \%$ for the worst case scenario, i.e., using the largest height to width ratio observed (approximately $1 / 10$ ) and a north-south running channel.

Observing geometry combined with roughness of the surrounding plains versus the channels could possibly explain the observations, although the explanation is quite strained. It requires the surrounding plains to have higher average slopes and more large scale roughness than the channel floors. The slopes facing the sun, and thus the warmest slopes, were also the slopes that faced the Termoskan instrument. Thus, rougher surroundings would have appeared warmer. However, IRTM observations found channels to have higher inertias, and IRTM obtained nighttime observations and multiple phase angle observations. Thus, the temperature variations observed by Termoskan are likely not caused by the "smoothness" of the channels alone.

\section{Aeolian Increase of Average Particle Size}

Visible wind streaks and intracrater splotches in the areas surrounding the channels and general circulation model (GCM) surface wind predictions [Greeley et al., 1993] indicate that 
TABLE 3. Derived Inertias, Summary of Results From Previous Studies, and Model Albedos Used

\begin{tabular}{|c|c|c|c|c|c|c|}
\hline Channel & Channel I & Surr. I & Delta I & Previous Channel Results From Thermal Studies & Chan. A & Surr. A \\
\hline Al-Qahira & $8.7(0.9)$ & $7.3(0.4)$ & $1.4(0.8)$ & [Z86]: In combination with Ma'adim: $3.5-12.5$ with mode 8 . & 0.21 & 0.21 \\
\hline Ma'adim & $9.3(0.9)$ & $7.3(0.4)$ & $2.1(0.8)$ & [Z86]: In combination with Al-Qahira: 3.5-12.5 with mode 8. & 0.21 & 0.21 \\
\hline Shalbatana & 9.0 & 6.2 & 2.8 & $\begin{array}{l}\text { [CK79]: 7-8+, thermally distinguishable south of } 10^{\circ} \mathrm{N} \text {. } \\
\text { [C88]: 9-12, not correlated with dark materials; rock } \\
\text { abundance as high as } 14 \% \text {. }\end{array}$ & 0.24 & 0.24 \\
\hline $\begin{array}{l}\text { Hydraotes } \\
\text { Channel }\end{array}$ & 12.5 & 9.0 & 3.5 & $\begin{array}{l}\text { [CK79]: } 12-13 \text { near chaos. } \\
\text { [PK81]: near } 11 \text {, although most of the bins sample significant } \\
\text { portions of the surrounding plateau as well. } \\
\text { [C86]: Relatively high rock abundance, }>14 \% \text { in some } \\
\text { places, although not well resolved from surroundings. }\end{array}$ & 0.17 & 0.20 \\
\hline Simud Vallis & 8.4 & 7.4 & 1.1 & [CK79]: 8-10, thermally distinguishable S. of $10^{\circ} \mathrm{N}$. & 0.24 & 0.24 \\
\hline Tiu West & 10.6 & 9.3 & 1.3 & [CK79]: 11-12; thermally distinguishable S. of $10^{\circ} \mathrm{N}$. & 0.22 & 0.22 \\
\hline Tiu East & 11.0 & 8.6 & 2.4 & [CK79]: 10-11; thermally distinguishable S. of $10^{\circ} \mathrm{N}$. & 0.24 & 0.24 \\
\hline $\begin{array}{l}\text { Gangis } \\
\text { Chasma }\end{array}$ & 10.4 & 7.8 & 2.6 & & 0.19 & 0.19 \\
\hline Eos Chasma & 19.9 & 15.6 & 4.4 & & 0.17 & 0.17 \\
\hline
\end{tabular}

Abbreviated column headings are as follows: Channel I, derived channel inertias $\left(10^{-3} \mathrm{cal} \mathrm{cm}^{-2} \mathrm{~K}^{-1} \mathrm{~s}^{-1 / 2}\right.$, multiply by 41.86 for SI units); Surr. I, derived inertias for the surroundings; Delta I, average inertia difference between paired points in channel and outside channel; Chan. $\mathrm{A}$, albedo used for channel in thermal model: Surr. A, albedo used for surroundings in thermal model, from Pleskot and Miner [1981].

Numbers in parentheses represent standard deviations, presented to give an idea of the range in inertias. These do not represent errors, since the data were collected for several points within the channels and on the surroundings that actually have different inertias.

Previous results are from the following sources: [CK79], Christensen and Kieffer [1979] (note that inertia numbers were read off their contour plots based upon $1 / 2^{\circ} \times 1 / 2^{\circ}$ bins, whereas descriptions are derived from their text); [PK81], Palluconi and Kieffer [1981] (data from $2^{\circ} \times 2^{\circ}$ bins); [C86], Christensen [1986]; [Z86], Zimbelman [1986], includes portions of the channels that were not observed by Termoskan; and [C88], Craddock et al. [1988], includes portions of the channels that were not observed by Termoskan.

Channel I and Delta I are probably lower bounds (see text).

Our derived inertias for the surroundings are in good agreement with the corresponding $2^{\circ} \times 2^{\circ}$ binned inertias of Palluconi and Kieffer [1981], with the average inertia difference (Termoskan derived inertia minus Palluconi and Kieffer inertia) between paired points being +0.3 with a standard deviation of 0.8 .

Derived inertias for Eos Chasma are probably much too high due to the so-called aftemoon cooling effect, in which the surface of Mars is observed to cool much faster in the afternoon than predicted by thermal models of the type used here [Jakosky, 1979; Ditteon, 1982]. Eos Chasma, observed at $15.2 \mathrm{H}$, was the only channel observed after $13 \mathrm{H}$, and hence the only channel for which this was a major factor. For reference, the Palluconi and Kieffer [1981] inertia for the area modeled as the Eos Chasma surroundings was 9.2, versus the 15.6 derived here.

Inertias were not derived for Ravi or Ares Valles because their temperatures generally appear similar to their surroundings.

aeolian processes have been and are probably still active in the channel regions studied here. In addition, the channels may focus winds or create them preferentially due to differential heating of walls versus the floors [Craddock et al., 1988], although this is less likely for the widest channels. We agree with previous studies that localized dark splotches and streaks within the channels are probably aeolian sand deposits [Christensen and Kieffer, 1979; Zimbelman, 1986; Craddock et al., 1988]. The question remains, however, whether aeolian processes are responsible for the enhanced inertia of the rest of the channels. Possible aeolian causes include (1) small-scale deposition, i.e., between rocks, but not burying all rocks; (2) large-scale depositional blankets; and (3) deflation, i.e., windinduced removal of fine material, exposing higher inertia material. Because a blanket of suspension (dust) sized particles within a channel would cause a lower inertia, not the observed higher inertia, we consider only saltation sized particles.

The thermal homogeneity of the channel floors argues against any type of aeolian process, short of a uniform sand sea, causing the channel inertia enhancement. Aeolian processes on Earth and as observed on Mars inevitably cause spatial heterogeneity. This is consistent with having localized, dark deposits within channels. Based upon Earth analogs, most of the saltating material will keep moving until it reaches and piles up in lower wind velocity / adverse slope traps such as the observed dark deposits. The exact correlation of inertia with flat floor bottoms is also inconsistent with an aeolian explanation. One would expect an aeolian process to spread some of its thermal signature onto terraces or against walls. That is exactly what is observed in the visible with some localized dark deposits that do spread out onto the surrounding plains (e.g., see southern Shalbatana Vallis and also Hydraotes Channel in Figure 2). Aeolian explanations, whether depositional or deflational, are also inconsistent with the thermal homogeneities in serpentine regions of the channels, such as around buttes in northem Hydraotes Chaos.

A several centimeter thick sand blanket within the channels, although perhaps consistent with the thermal homogeneity, is inconsistent with other observations. One would expect a complete sand blanketing to spread somewhat to the surroundings. Also, the visible heterogeneity seen in some places may be inconsistent with a sand sea. Dune features are also not obvious throughout the channels in Viking images, although resolution is a problem. 
Preferential aeolian deflation within the channels also seems inadequate to explain the overall inertia enhancement, although it may play some role. As with aeolian deposition, one would expect aeolian deflation to cause greater thermal heterogeneity, particularly in serpentine channel regions. Any topographic obstacle or channel bend would presumably affect the amount of deflation and eventual deposition of particles. An even greater difficulty with aeolian deflation as a sole explanation is that to match the observations, it must uniformly strip flat floors, but not buttes, benches, or the surroundings. Then, even if aeolian deflation has taken place, what remains on the surfaces of the floors? Deflation could not have been too effective stripping the channels down to rock. The observed inertias are far below the inertias of at least 30 or 40 expected for bare rock on Mars. Although rock abundances for some channels are higher than average Mars, they are still probably less than 20\% (based upon Christensen [1986] and Craddock et al. [1988]). Thus, even deflation would have to leave significant fines behind. This could be accomplished by bonding of the fines, some kind or armoring of the surface by rocks, or a self-limiting stripping process where a natural limit is reached on the amount of saltating fine material that can be stripped away (M. C. Malin, personal communication, 1993). However, one still has difficulty explaining thermal homogeneity and flat floor thermal correlation, including in serpentine regions.

\section{Channel Formation Processes: Fretting Versus Flooding}

Two categories of channel formation processes may have resulted in channel inertia enhancement: catastrophic flooding or fretting. Most of the thermally distinct portions of observed channels have flat, wide floors devoid of large-scale bedforms. Steep, sometimes scalloped, walls are also associated with most thermally distinct channels. These morphologies are indicative of fretting [Sharp, 1973]. Eastern Ravi (Figure 2) and southern Ares (Figure 3) are the only major channel sections observed that are not clearly thermally distinct. They also are the only major channel sections observed that have bedforms clearly indicative of catastrophic flooding, but not fretting [Sharp and Malin, 1975; Baker, 1982]. Thus, we favor fretting over catastrophic flooding as the cause of the inertia enhancements that are observed.

Fretting here refers to wet or dry sapping, mass wasting, and possible debris flow [Sharp, 1973], although we emphasize that it is not a well-understood process. For example, Baker and Kochel [1979] identified a whole range of mass movement, slope, and periglacial features associated with scalloped and fretted channel margins. Significantly, these features did contrast with the suite of cataclysmic flood bedforms found on the floors of some channels [Baker and Milton, 1974]. Fretting is morphologically well defined for Mars, and it does contrast with channels showing well-defined catastrophic flooding bedforms. Thus, whatever the exact fretting processes, fretted morphologies do appear to be associated with the channels showing enhanced inertias in this study. Although catastrophic flooding undoubtedly occurred in some of these channels, fretting likely followed. Only the last significant process to affect the channels will affect the upper few centimeters that are sensed by diurnal thermal measurements.

Chaotic terrain is often associated with nearby fretted areas, such as in the Hydraotes Chaos region. Chaotic terrain may represent an intermediate stage that in some cases was eventually smoothed to form fretted areas [Sharp, 1973]. It often has enhanced inertia (e.g., in Hydraotes Chaos) as observed both in the Termoskan data and in IRTM data [e.g., Christensen and Kieffer, 1979]. These inertia enhancements could be related to early stages of fretting.
Fretting as a general cause of channel inertia enhancements may be consistent with IRTM thermal studies of channel regions not observed by Termoskan. Christensen and Kieffer [1979] found Simud, Tiu, and Shalbatana Valles to have inertia enhancements south of $10^{\circ} \mathrm{N}$, but not north of there. To the north, these channels show increased catastrophic flooding bedforms on their floors such as grooves, and they do not commonly have steep, scalloped walls. Christensen and Kieffer found that higher inertia on the floor of Ares Vallis was most apparent north of $10^{\circ} \mathrm{N}$ and in a region near $7^{\circ} \mathrm{N}$. Some of these portions of Ares are not obviously fretted, but most do not show obvious catastrophic flooding floor features as do the least thermally distinct portions south of about $6^{\circ} \mathrm{N}$ [Sharp and Malin, 1975].

Kasei Valles, found by Christensen and Kieffer [1979] to have enhanced inertia, was classed as a modified fretted channel by Sharp and Malin [1975]. Although it may show significant catastrophic flooding features in certain regions, it was likely last modified in most regions by fretting type processes [Baker, 1982]. Craddock et al. [1988] reported that Mangala Vallis did not appear thermally distinct from its surroundings. It shows significant catastrophic flooding floor features over much of its length [Sharp and Malin, 1975; Baker, 1982]. Thus, although it is speculative to extend a fretting explanation to a wider range of channels without higher resolution thermal data, IRTM data do seem generally consistent with a fretting explanation. Future missions' increased global coverage will allow a more thorough testing of the generality of the fretting hypothesis.

Fretting could have increased channel inertias either by increasing the average rock abundance versus the surroundings, or by preferentially increasing the bonding of fine particles. We consider these two possibilities in turn.

Increased rock abundance. An increased areal percentage of rocks (in the form of boulders, cobbles, gravel, or even pebbles) could be the cause of the channel inertia enhancement. Rocks may have been emplaced as debris derived from fretting, although it would have been challenging to both transport the rocks several kilometers to several tens of kilometers and still preserve a relatively uniform thermal inertia floor signature. However, particularly given the uncertainty of the fretting process, this may have been possible. IRTM data indicate that rock abundances are higher for some channels including Shalbatana Vallis [Craddock et al., 1988] than for the surrounding terrains. The percentages of rocks found, although high for Mars, are still nowhere near a complete covering of the surface. Thus, a finer clastic component still must play a significant role in determining inertia.

Bonding of fine materials. Variations in maturity of a duricrust (i.e., degree of bonding of a case-hardened crust) were suggested by Jakosky and Christensen [1986] to explain most of the low resolution thermal inertia variations on Mars. Areas where fines have been more efficiently bonded will have higher thermal inertias due to increased thermal conductivity. Duricrusts were observed at the Viking Lander sites [Binder et al., 1977; Mutch et al., 1977]. Water and/or salts were proposed as the agents of duricrust formation [Jakosky and Christensen, 1986]. Fretting may have increased bonding of fine materials within the channels due to increased presence of water and possibly brines either initially or secondarily.

Whether of primary or secondary origin, water for the bonding of materials was likely more accessible on the low, flat channel bottoms than on the surrounding plateaus or on the intermediate inertia benches. Bonding is also largely consistent with thermal variations strictly following the channel bottoms, even in 
serpentine regions. The absolute inertia values of the channels are consistent with values that could be obtained by bonding fine materials in combination with some rocks on the surface. The channel inertias are similar to somewhat higher inertias in the areas of the Viking Landers (approximately 9 and 8 [Kieffer, 1976]). The lander sites showed relatively thin duricrusts as well as relatively high percentages of rocks [Binder et al., 1977; Mutch et al., 1977].

In addition to being consistent with the idea of Jakosky and Christensen [1986] that most inertia variations on Mars are due to variations in duricrust maturity, increased bonding in channels is also consistent with Christensen's [1986] finding that most thermal inertia variations on Mars are due to variations in the fine component inertia, not the percentage of blocks. This theory does not explain the increased rock abundances found in some channels, but it is consistent with findings that regions with higher rock abundances generally have higher fine-component inertias [Christensen, 1986].

Increased water or brines on channel floors may have come from the initial fretting due to sapping water flow or ice flow. This would require that the fines already be present on the surface at the time of channel floor formation and that the bonded material survive since the time of channel formation, which is difficult considering the long time since formation and the relative activity of the surface. In particular, dust storm fallout must be dealt with. One possible scenario is that aeolian deflation strips the new dust fallout off over time. This combined theory of aeolian deflation is favored over deflation alone because the surroundings can be stripped simultaneously, but the result reexposes the bonded material. Thus, the channel alone does not have to be preferentially stripped and a relatively uniform surface will be exposed. There is an alternative that does not require the original surface to be preserved and that keeps many of the attractive features of a bonding theory.

Water may have been preferentially present on fretted channel floors after initial channel floor formation. Fretting may have emplaced water or ice near the surface, or the uniform floor level of fretted channels may represent the original depth of frozen ground [Sharp, 1973]. Processes acting over long time scales such as evaporation, adsorption and diffusion, or some other process may then have provided water at the very surface that accentuated the bonding of fines. The actual material bonded could have been original or could have been dust that was deposited over time in the channels as a result of dust storm fallout. Post floor formation bonding would be consistent with the apparent Termoskan observation that landslides and ejecta blankets appear thermally similar to the surrounding channel floors. However, these features are just at the limit of Termoskan's resolution, so this observation will have to be confirmed with future higher resolution missions.

Thus, post floor formation bonding avoids some of the difficulties involved with preserving an original surface. The theory is somewhat speculative, however, given uncertainties on how this mechanism would act and at what rates. Whatever the actual process, the association of water with the formation of the channels and the location of channel floors closer to water and ice tables argue for the hydrologic plausibility of a preferential bonding explanation.

\section{SUMMARY AND CONCLUSIONS}

Utilizing the Termoskan data, we conclude that channels on Mars generally have higher thermal inertia than their surroundings, consistent with IRTM studies. For the first time, we observe that the thermal inertia boundaries very closely match flat channel floor boundaries. Atmospheric and geometric effects are not sufficient to cause the observed inertia enhancement. We agree with previous researchers that localized, dark, high-inertia areas within channels are likely aeolian in nature. We disagree with some researchers that aeolian deposits fill the channels or are responsible for the overall thermal inertia enhancement. Small-scale aeolian deposition or aeolian deflation may play roles in the inertia enhancement. However, largely because of the thermal homogeneity of the channel floors, we favor alternate explanations.

Fretting or catastrophic flooding may have emplaced more rocks on channel floors or caused increased bonding of fines due to the presence of water. We favor fretting processes over flooding for the cause of the higher thermal inertia because of the flat floors and steep scalloped walls in most regions that show inertia enhancements. Alternatively, at some time after channel formation, water that was preferentially present due to the low, flat fretted floors may have enhanced bonding of original fines or dust fallout. Future missions should be able to distinguish between competing theories of inertia enhancement. The possibility that the flat channel floors owe their high inertia to water-related processing (bonding of fines) argues for assigning high priority to these sites in future exploration.

The loss of Mars Observer (MO) occurred while this paper was being revised. We still have chosen to include a discussion of MO instruments and their potential contribution to the study of channels and valleys because the comments will be generally applicable to whatever analogous instruments may fly on future Mars missions. The unprecedented high resolution of the Mars Observer Camera (MOC) (up to $1.4 \mathrm{~m} / \mathrm{pix}$ el [Malin et al., 1992]) would have enabled channel floor surface morphologies indicative of aeolian, flooding, or fretting processes to be recognized. These morphologies may include: dunes, water flow morphologies, large boulders, and some mass wasting features. The Mars Observer laser altimeter (MOLA) profiles, with a vertical precision of about $2 \mathrm{~m}$ and horizontal resolution of about $300 \mathrm{~m}$ [Zuber et al., 1992], would have complemented MOC by providing detailed topographic information and some roughness information that would show how flat and smooth the floors really are and how steep the walls are, allowing slope versus angle of repose comparisons for the walls. The high resolution stereo camera (HRSC) on Mars '94 (M94) is designed to obtain both high-resolution imaging and topographic information.

Also on MO, TES [Christensen et al., 1992] and the pressure modulator infrared radiometer (PMIRR) [McCleese et al., 1992], via global thermal inertia and albedo coverage, would have given insight into the origin of the channel inertia enhancements. The correlation of channel inertia enhancements with fretted morphologies versus purely catastrophic flood morphologies would have been tested globally. TES also would have contributed significantly to understanding the small-scale cause of the enhancements via rock abundances and fine-component inertias in $3 \mathrm{~km} /$ pixel maps derived using multiwavelength methods similar to Christensen [1983, 1986]. Thus, increasedrock theories could have been evaluated versus increased-finecomponent processes, whether larger particles or bonding. TES spectral mapping would have indicated compositional differences between channels and surroundings.

Termoskan 2 on M94 is expected to increase spatial resolution another order of magnitude from most of the Termoskan 1 data. The high spatial resolution targeted upon channels will enable tests of whether the thermal signal remains uniform at those resolutions. In addition, Termoskan 2 can observe more channels of varying morphologies elsewhere on Mars. Observations of 
small craters and their ejecta and landslides will test inertia enhancement theories and timescales.

The Omega imaging spectrometer on M94 is designed to give important near-IR spectral information about the channels. In particular, Omega is designed to map trace amounts of hydrated minerals as was done at lower resolution for other Mars regions with the Phobos '88 imaging spectrometer for Mars (ISM) instrument [Erard et al., 1991]. We would expect enhanced hydration signatures for the channel floors if significant bonding and duricrust formation has occurred. Thermally distinctive channel floors also represent interesting locations for future landers due to their unique history and the probable surface presence of material from various stratigraphic layers and locations.

-Acknowledgments. We thank Phil Christensen and Vic Baker for thoughtful reviews of the submitted manuscript, Michael Malin for helpful discussions, and Doug Nash, Dewey Muhleman, and Andy Ingersoll for helpful comments on the manuscript. Also, thanks to Jan Yoshimizu for help in producing prints of the images. Funding for this research was provided by NASA grants NAGW-1426 and NAGW-2491. Division of Geological and Planetary Sciences, Califomia Institute of Technology contribution 5287.

\section{REFERENCES}

Baker, V. R., The Channels of Mars, University of Texas Press, Austin, 1982.

Baker, V. R., M. H. Carr, V. C. Gulick, C. R. Williams, and M. S. Marley, Channels and valley networks, in Mars, edited by $\mathrm{H}$. Kieffer et al., pp. 493-522, University of Arizona Press, Tucson, 1992.

Baker, V. R., and R. C. Kochel, Martian channel morphology: Maja and Kasei Valles, J. Geophys. Res., 84, 7961-7983, 1979.

Baker, V. R., and D. J. Milton, Erosion by catastrophic floods on Mars and Earth, Icarus, 23, 27-41, 1974.

Betts, B. H., Themal and visible studies of Mars using the Termoskan data set, Ph.D. thesis, Calif. Inst. of Technol., Pasadena, 1993.

Binder, A. B., R. E. Arvidson, E. A. Guinness, K. L. Jones, E. C. Morris, T. A. Mutch, D. C. Pieri, and C. Sagan, The geology of the Viking Lander 1 site, J. Geophys. Res., 82, 4439-4451, 1977.

Carr, M. H., The Surface of Mars, Yale University Press, New Haven, Conn., 1981.

Carr, M. H., Mars: A water-rich planet, Icarus, 68, 187-216, 1986.

Christensen, P. R., Eolian intracrater deposits on Mars: Physical properties and global distribution, Icarus, 56, 496-518, 1983.

Christensen, P. R., The spatial distribution of rocks on Mars, Icarus, 68, 217-238, 1986.

Christensen, P. R., and H. H. Kieffer, Moderate resolution thermal mapping of Mars: The channel terrain around the Chryse Basin, J. Geophys. Res., 84, 8233-8238, 1979.

Christensen, P. R., and H. J. Moore, The Martian surface layer, in Mars edited by H. Kieffer et al., pp. 686-729, University of Arizona Press, Tucson, 1992.

Christensen, P. R., et al., Thermal emission spectrometer experiment: Mars Observer mission, J. Geophys. Res., 97, 7719-7734, 1992.

Clifford, S. M., C. J. Bartels, and E. P. Rubenstein, The Mars thermal model (MARSTHERM): A FORTRAN 77 finite-difference program designed for general distribution, Lunar and Planetary Institute, Houston, Tex., 1987.

Craddock, R. A., High resolution thermal infrared mapping of Martian outflow and fretted channels, M.S. thesis, Dep. of Geol., Ariz. State Univ., Tempe, 1987.

Craddock, R. A., R. Greeley, P. R. Christensen, and F. T. Aldrich, Martian channel materials and the formation of channel winds (abstract), Lunar Planet. Sci., XIX, 215-216, 1988.

Ditteon, R., Daily temperature variations on Mars, J. Geophys. Res., 87. 10,197-10,214, 1982.

Erard, S., J.-P. Bibring, J. F. Mustard, O. Fomi, J. W. Head, S. Hurtrez, Y. Langevin, C. M. Pieters, J. Rosenqvist, and C. Sotin, Spatial variations in composition of the Valles Marineris and Isidis Planitia regions derived from ISM data, Proc. Lunar Planet. Sci. Conf., 21st, 437-455, 1991.

Greeley, R., and J. E. Guest 1:15M Geologic map of the eastem equatorial region of Mars, U.S. Geol. Surv. Misc. Invest. Map, I-1802-B, 1987.

Greeley, R., A. Skypeck, and J. B. Pollack, Martian aeolian features and deposits: Comparisons with general circulation model results, J. Geophys. Res., 98, 3183-3196, 1993.

Haberle, R. M., and B. M. Jakosky, Atmospheric effects on the remote detemination of thermal inertia on Mars, Icarus, 90, 187-204, 1991.

Jakosky, B. M., The effects of nonideal surfaces on the dervied thermal properties of Mars, J. Geophys. Res., 84, 8252-8262, 1979.

Jakosky, B. M., and P. R. Christensen, Global duricrust on Mars: Analysis of remote sensing data, J. Geophys. Res., 91, 3547-3560, 1986.

Kieffer, H. H., Soil and surface temperalures at the Viking lander sites, Science, 194, 1344-1346, 1976.

Kieffer, H. H., S. C. Chase, Jr., E. Miner, G. Münch, and G. Neugebauer, Preliminary report on infrared radiometric measurements from the Mariner 9 spacecraft, J. Geophys. Res., 78, 4291-4312, 1973.

Kieffer, H.H., T.Z. Martin, A.R. Peterfreund, B.M. Jakosky, E.D. Miner, and F.D. Palluconi, Thermal and albedo mapping of Mars during the Viking primary mission, J. Geophys. Res., 82, 4249-4291, 1977.

Malin, M. C., G. E. Danielson, A. P. Ingersoll, H. Masursky, J. Veverka, M. A. Ravine, and T. A. Soulanille, Mars Observer camera, J. Geophys. Res., 97, 7699-7718, 1992.

Mars Channel Working Group, Channels and valleys on Mars, Geol. Soc. Am. Bull., 94, 1035-1054, 1983.

Masursky, H., A. L. Dial, Jr., and M. E. Strobell, Martian channels-A late Viking view, NASA Tech. Memo., 82385, 184-187, 1980.

McCleese, D. J., R. D. Haskins, J. T. Schofield, R. W. Zurek, C. B. Leovy, D. A. Paige, and F. W. Taylor, Atmosphere and climate studies of Mars using the Mars Observer pressure modulator infrared radiometer, $J$. Geophys. Res., 97, 7735-7758, 1992.

Murray, B.C., et al., Preliminary assessment of termoskan observations of Mars, Planet Space Sci., 39(1/2), 237-265, 1991.

Mutch, T. A., R. E. Arvidson, J. W. Head, K. L. Jones, and R. S. Saunders, The Geology of Mars, Princeton University Press, Princeton, N. J., 1976.

Mutch, T. A., R. E. Arvidson, A. B. Binder, E. A. Guinness, and E. C. Morris, The geology of the Viking Lander 2 site, J. Geophys. Res., 82, 4452-4467, 1977.

Palluconi, F. D., and H. H. Kieffer, Thermal inertia mapping of Mars from $60^{\circ} \mathrm{S}$ to $60^{\circ} \mathrm{N}$, Icarus, $45,415-426,1981$.

Pleskot, L.K., and E.D. Miner, Time variability of Martian bolometric albedo, Icarus, 45, 179-201, 1981.

Scott, D. H., and K. L. Tanaka, Geologic map of the westem equatorial region of Mars, U.S. Geol. Surv. Misc. Invest. Ser. Map, I-1802A, scale $1: 15,000,000,1986$.

Selivanov, A. S., M. K. Naraeva, A. S. Panfilov, Yu. M. Gektin, V. D. Kharlamov, A. V. Romanov, D. A. Fomin, and Ya. Ya. Miroshnichenko, Thermal imaging of the surface of Mars, Nature, 341, 593-595, 1989.

Sharp, R P., Mars: Fretted and chaotic terrains, J. Geophys. Res., 78, 40734083, 1973.

Sharp, R. P., and M. C. Malin, Channels on Mars, Geol. Soc. Am. Bull., 86, 593-609, 1975.

Squyres, S. W., Martian fretted terrain: Flow of erosional debris, Icarus, 34, $600-613,1978$.

U.S. Geological Survey, Mosaicked digital image model (MDIM), in Mission to Mars: Digital Image Map CD-ROM, vol. 1, Flagstaff, AZ, $1991 a$.

U.S. Geological Survey, Topographic map of Mars, U.S. Geol. Surv. Misc. Geol. Inv. Map, I-2179, 1991 b.

Zimbelman, J.R., Themal properties of channels in the aeolis quadrangle: Topographic traps for aeolian materials, in Symposium on MECA, pp. 112-114, Lunar and Planetary Institute, Houston, Tex., 1986.

Zimbelman, J.R., and L.A. Leshin, A geologic evaluation of thermal properties for the Elysium and Aeolis quadrangles of Mars, Proc. Lunar Planet. Sci. Conf. 17th, Part 2, J. Geophys. Res., 92, suppl., E588-E596, 1987.

Zuber, M. T., D. E. Smith, S. C. Solomon, D. O. Muhleman, J. W. Head, J. B. Garvin, J. B. Abshire, and J. L. Bufton, The Mars Observer laser altimeter investigation, J. Geophys. Res., 97, 7781-7798, 1992.

B. H. Betts, San Juan Capistrano Research Institute, 31872 Camino Capistrano, San Juan Capistrano, CA 92675.

B. C. Murray, Planetary Science 170-25, California Institute of Technology, Pasadena, CA 91125.

(Received June 28, 1993; revised November 5, 1993;

accepted November 9,1993 .) 